\title{
Conhecimentos e necessidades de aprendizagem relacionadas à enfermidade cardíaca para hipertensos revascularizados em reabilitação ${ }^{1}$
}

\section{Knowledge and learning needs associated with cardiac nursing for revascularized hypertensive patients in rehabilitation}

\section{Conocimientos y necesidades en relación al aprendizaje sobre la enfermedad cardíaca en hipertensos revascularizados en rehabilitación}

\author{
Natállia Guimarães Mansano', Vanessa da Silva Carvalho Vila", Lídia Aparecida Rossi'II \\ 1 Extraído da pesquisa de iniciação científica: A necessidade de aprendizagem na perspectiva de hipertensos submetidos à cirurgia de \\ revascularização do miocárdio. \\ ' Acadêmica do 9o período do Curso de Graduação em Enfermagem da Universidade Católica de Goiás (UCG) e Bolsista de iniciação científica. \\ Email: natmansano@yahoo.com.br. \\ "Doutora em Enfermagem. Orientadora do Projeto de Pesquisa no Núcleo de Estudos e Pesquisa em Saúde e Sociedade da UCG. Email: \\ vscvila@uol.com.br. \\ III Doutora em Enfermagem e Professor Associado do Departamento de Enfermagem Geral e Especializada da Escola de Enfermagem de \\ Ribeirão Preto da Universidade de São Paulo. Email: rizzardo@eerp.usp.br.
}

\section{RESUMO}

Estudo de caso qualitativo desenvolvido com o objetivo de identificar os conhecimentos e as necessidades de aprendizagem relacionados à enfermidade cardíaca em hipertensos submetidos à revascularização miocárdica. Os dados foram coletados por meio de entrevistas semi-estruturadas realizadas no domicílio de doze indivíduos. Observou-se que os sujeitos não imaginavam que o mal-estar, a dor no peito e no estômago pudessem ser um problema no coração. A maior parte não percebera o risco de desenvolver a doença cardíaca associado a fatores com os quais já convivia, como a hipertensão. Ao buscarem explicações para a doença cardíaca, muitos deles relataram que vivenciavam situações de estresse, ingeriam comidas gordurosas, fumavam, bebiam, não praticavam exercícios físicos, não iam ao médico e se preocupavam apenas com o trabalho e a provisão financeira da família. As necessidades de aprendizagem relacionaram-se à compreensão sobre as causas da coronariopatia e da hipertensão e os cuidados preventivos para lhes assegurar boa saúde e qualidade de vida. Os resultados mostraram a importância da utilização pelos profissionais de estratégias de educação em saúde que satisfaçam as necessidades de conhecimento dos indivíduos acerca do processo saúde e doença e que contribuam para que, efetivamente, eles incorporem às suas vidas atitudes que promovam saúde.

Descritores: Hipertensão; Educação em Saúde; Revascularização Miocárdica.

\section{ABSTRACT}

This is a qualitative case study that aimed to identify the knowledge and learning needs that hypertensive patients submitted to myocardial revascularization have about cardiac nursing. The data were collected through semi-structured interviews performed at the homes of twelve subjects. Data analysis revealed that the subjects were not aware that feeling sick, or experiencing chest and stomach pain could mean having a heart condition. Most did not realize the risk of developing heart disease associated with the factors with which they already lived, like having high blood pressure. When they searched for explanations for their heart condition, they reported they experienced stressful situations, ate fatty foods, smoked, drank, did not exercise, did not visit their doctor regularly, and were mainly worried about work and looking after their family financially. The learning needs were associated with understanding what caused the coronary disease and hypertension and the preventive care they should follow to have good health and quality of life. The results proved that it is important that professionals use health education methods that cover the patients' knowledge needs regarding the health-disease process and that would effectively contribute with their complying with health-promotion attitudes.

Descriptors: Hypertension; Health education; Myocardial revascularization.

\section{RESUMEN}

Estudio de caso de tipo cualitativo. Tuvo por objetivo identificar el conocimiento y la necesidad en relación al aprendizaje sobre la enfermedad cardiaca en hipertensos sometidos a revascularización del miocardio. Los datos fueron recolectados en los respectivos domicilios de los doce participantes, mediante entrevistas semiestructuradas. A través del análisis se comprobó que los sujetos no pensaban que el malestar, el dolor en el pecho y en el estómago, pudieran ser debido a algún problema cardiaco. La mayoría no percibió el riesgo para enfermedad cardiaca asociada a factores presentes, tal como la hipertensión arterial. Al buscar explicaciones sobre la enfermedad, mencionaron pasar por momentos de estrés, ingerir comida grasosa, fumar, beber, no practicar ejercicios físicos, no realizar consultas al médico, dando casi toda su atención al trabajo y a la economía familiar. Las necesidades de aprendizaje estuvieron relacionadas a: comprender la causa de la enfermedad, la hipertensión arterial y a la prevención para obtener buena salud y calidad de vida. Los resultados mostraron la importancia en utilizar métodos educativos en salud por parte de los profesionales. En donde, se considere a los individuos participantes en relación a la necesidad de conocimiento sobre el proceso de salud- enfermedad; lo cual, contribuirá de forma efectiva en sus vidas para la incorporación de actitudes que promuevan su salud.

Descriptores: Hipertensión; Educación en Salud; Revascularización Miocárdica. 


\section{NTRODUÇÃO}

O tratamento dos indivíduos portadores de doença isquêmica cardíaca vem experimentando avanços terapêuticos, clínicos e cirúrgicos nos últimos 30 anos. Neste contexto, a cirurgia de revascularização do miocárdio (RVM) é um dos procedimentos cirúrgicos mais realizados em decorrência da doença arterial coronariana (DAC). No entanto, a realização da cirurgia resolve apenas em parte o problema vivenciado, pois, em geral, a maioria dos pacientes coronariopatas convive com fatores de risco, tais como diabetes, sedentarismo, tabagismo e hipertensão arterial sistêmica, esta uma das principais causas de óbito por complicações cardiovasculares $^{(1)}$.

A principal meta terapêutica para indivíduos coronariopatas revascularizados deveria ser a reabilitação cardíaca, definida como um processo de desenvolvimento e manutenção de níveis desejáveis de atividade física, social e psicológica após o início da doença cardiovascular. Especificamente, envolve a combinação de programa de condicionamento físico e propostas educacionais voltadas para a redução da gravidade da doença, a detenção de sua progressão, a identificação de fatores de risco, como a hipertensão arterial, e, finalmente, a educação e a capacitação desses indivíduos para que empreendam a necessária mudança de comportamento e a adequação do estilo de vida para promoção da saúde, compreendendo a saúde como um processo que envolve o bem-estar físico, emocional e social ${ }^{(2)}$.

A hipertensão arterial sistêmica (HAS) é considerada um dos principais fatores relacionados à morbimortalidade cardiovascular. É descrita como uma doença multifatorial, crônica e de detecção quase sempre tardia em conseqüência de seu curso assintomático e prolongado ${ }^{(3-4)}$. A reabilitação de indivíduos coronariopatas hipertensos revascularizados deve ser considerada de fundamental importância para a manutenção da qualidade de vida desses pacientes, evitando-se, assim, que sejam novamente hospitalizados ou sofram complicações futuras decorrentes da nãoconscientização do potencial risco de recidiva da coronariopatia.

Embora esteja comprovada sua efetividade no tratamento, a manutenção da pressão arterial dentro de níveis desejáveis ainda é insatisfatória. O tratamento para o controle da hipertensão arterial inclui, além da utilização de medicamentos, a modificação de hábitos de vida, de forma que sejam priorizadas as medidas de prevenção que promovam a adoção de um estilo de vida saudável ${ }^{(5-6)}$.

Neste contexto, a educação em saúde pode ser considerada importante estratégia para estimular e influenciar, verdadeiramente, o comportamento, visando promover mudanças de hábitos e do estilo de vida para que haja o controle efetivo da hipertensão arterial nos pacientes revascularizados ${ }^{(2,6)}$. Educação em saúde pode ser definida como um processo que aumenta o conhecimento e a aquisição de habilidades que influenciam as atitudes do paciente para que mantenha o controle adequado de sua saúde e, com isso, favoreça a qualidade de vida. Além da informação, é necessário que os profissionais de saúde proponham ações educativas que possibilitem a identificação das crenças, dos valores, das condições de saúde e dos serviços de apoio existentes no processo de reabilitação, considerando o contexto de vida sociocultural dessas pessoas ${ }^{(4,7-8)}$.

O enfermeiro tem um importante papel no cuidado dessas pessoas, cujo foco são as ações de prevenção por meio da educação conscientizadora, considerando que a pessoa poderá vivenciar novamente 0 problema cardíaco caso não haja adesão ao tratamento, mudança no estilo de vida e ações direcionadas ao autocuidado(4).

Assim, este estudo foi desenvolvido com o objetivo de identificar os conhecimentos e as necessidades de aprendizagem relacionadas à enfermidade cardíaca em indivíduos hipertensos revascularizados, ressaltando-se a importância de que os profissionais identifiquem o conhecimento do senso comum, as dificuldades e os comportamentos dos indivíduos ao vivenciarem este processo em sua vida privada e comunitária.

\section{TRAJ ETÓRI A METODOLÓGI CA}

Optou-se por realizar um estudo de caso qualitativo, que consiste no estudo aprofundado e exaustivo de um ou mais casos, de forma que seja possível o seu conhecimento amplo e detalhado. "O estudo de caso é um estudo empírico que investiga um fenômeno atual dentro de seu contexto real, quando as fronteiras entre o fenômeno e este contexto não estão claramente definidas"(9). A preocupação central deste tipo de pesquisa é a compreensão do caso, que pode ser simples ou complexo, individual ou coletivo, pois constitui uma representação singular da realidade que é multidimensional e historicamente situada ${ }^{(9)}$.

O presente estudo focalizou a realidade vivenciada por indivíduos hipertensos coronariopatas que realizaram a cirurgia de revascularização em uma instituição hospitalar, filantrópica, de grande porte, na cidade de Goiânia, Goiás, os quais concordaram em participar do estudo.

Após a aprovação do Comitê de Ética da instituição (Protocolo no 053/06), iniciou-se o trabalho de campo. Os dados foram coletados entre agosto de 2006 e março de 2007.

Participaram do estudo 12 indivíduos coronariopatas revascularizados que atendiam aos seguintes critérios: hipertensos em acompanhamento 
no ambulatório de cardiologia, cujo tempo de pósoperatório fosse de, no mínimo, três meses e, no máximo, dois anos, residissem na região metropolitana de Goiânia, maiores de 18 anos, e que concordassem em participar do estudo. Foram considerados inelegíveis os pacientes submetidos à cirurgia de RVM concomitantemente com outra cirurgia torácica (como correção ou troca de válvulas) e que possuíssem doenças psiquiátricas como demência e esquizofrenia.

Para a coleta de dados, foram realizadas entrevistas semi-estruturadas seguidas da observação do contexto dessas entrevistas. Assim, a pesquisadora pôde conhecer o ponto de vista dos sujeitos acerca do que consideravam necessário conhecer e aprender sobre a coronariopatia e a hipertensão arterial. Foi utilizado o critério de saturação de conteúdo para finalizar a coleta de $\operatorname{dados}^{(10)}$.

As entrevistas foram agendadas de acordo com a disponibilidade dos sujeitos da pesquisa e da pesquisadora e realizadas no domicílio de cada participante, por ser um local que garantia a privacidade, além de proporcionar-lhe comodidade e conforto. Antes de iniciar as entrevistas, o objetivo do trabalho foi explicado a todos os participantes, os quais assinaram o Termo de Consentimento Livre e Esclarecido e autorizaram a gravação da entrevista para análise dos dados.

As questões norteadoras das entrevistas foram: "Conte-me o que aconteceu com você", "Como tudo começou?", "O que você sabe sobre sua doença?", "O que você gostaria de saber sobre sua doença?", "O que é hipertensão arterial?", e "Qual a relação da hipertensão arterial com a doença arterial coronariana?". Ressaltamos que essas questões norteadoras iam sendo definidas à medida que acontecia a coleta e análise dos dados. Portanto, passaram por readequação de acordo com as necessidades e objetivos do estudo. Além dessas, foram elaboradas para cada sujeito outras questões de contraste específicas para seu relato ${ }^{(10)}$.

A análise de dados aconteceu durante todo o trabalho de campo, desde a seleção dos possíveis participantes até a redação do relatório de pesquisa, construído com base na descrição dos dados e na interpretação de seus significados no contexto pesquisado. Inicialmente, realizou-se a leitura exploratória e analítica das transcrições e notas de campo para que fosse possível a redução e a organização dos dados. A seguir, procedeu-se à leitura interpretativa para a identificação dos núcleos temáticos e temas. É importante salientar que a construção de núcleos temáticos e temas consistiu na busca pela identificação dos conhecimentos e aprendizagens necessários ao grupo social pesquisado. A etapa final foi a interpretação dos sentidos e significados expressos pelos sujeitos e a discussão com base no referencial teórico, nas percepções e reflexões do pesquisador. Aqui, a ferramenta principal foi a comparação, que permitiu destacar as semelhanças e diferenças e, assim, obter conclusões que foram comparadas com outros estudos $^{(11-12)}$.

\section{RESULTADOS E DI SCUSSÃO}

A análise dos dados possibilitou a descrição das características sociodemográficas dos participantes do estudo, a identificação dos temas e dos respectivos núcleos temáticos relacionados à necessidade de aquisição de conhecimentos e aprendizagens sobre a enfermidade cardíaca por parte dos indivíduos hipertensos.

\section{Caracterização sociodemográfica participantes do estudo}

dos

O grupo social pesquisado compunha-se de 12 indivíduos hipertensos revascularizados, oito homens e quatro mulheres, com idades variando de 44,7 a 73 anos. Dos participantes, nove eram casados, com cerca de três filhos. Quanto ao aspecto das religiões, cinco eram evangélicos, quatro católicos e três espíritas.

Em relação ao nível de escolaridade, quatro possuíam o segundo grau completo; três, o primeiro grau incompleto; dois, o segundo grau incompleto; um, o primeiro grau completo; um, o ensino superior incompleto e um era analfabeto. Estudos demonstram que os indivíduos com baixa escolaridade apresentam maior exposição aos fatores de risco para as doenças cardiovasculares, inclusive para o desenvolvimento da hipertensão arterial, do que aqueles com nível superior. Este dado é relevante já que poderá interferir indiretamente na assimilação das informações necessárias ao tratamento $^{(3,13)}$.

O tempo de pós-operatório variou de 7,5 a 32,0 meses. Sete sujeitos realizaram de três a quatro enxertos coronarianos, três fizeram de um a dois enxertos e dois receberam mais de quatro enxertos coronarianos. Dos 12 indivíduos hipertensos, cinco eram diabéticos, todos tinham dislipidemia e afirmaram não fumar, embora oito fossem extabagistas.

Durante a coleta de dados, tanto no ambulatório quanto no domicílio, observou-se que a maioria apresentava dificuldades no entendimento acerca das causas de sua doença e dos cuidados pós-operatórios necessários para sua recuperação, especialmente quanto ao uso da medicação para controle da pressão arterial e à mudança dos hábitos de vida. Muitos consideravam a medicação anti-hipertensiva desnecessária e que a prescrição de mais de uma medicação era excesso de cuidado do médico. 
Em relação à situação profissional, dos doze participantes, quatro trabalhavam e, após a cirurgia, voltaram a exercer sua atividade profissional; seis indivíduos já estavam aposentados antes da cirurgia e, destes, um ainda desempenhava atividade remunerada para complementar a renda familiar; um estava aguardando aposentadoria e outro estava inativo. A renda mensal variou de $\mathrm{R} \$ 350,00$ a $\mathrm{R} \$ 2.000,00$. A mediana da renda mensal foi de 700,00 reais, o que correspondia a dois salários mínimos na época do estudo.

Para os participantes, o maior impacto da doença sobre suas vidas foi no trabalho, tanto nas atividades do dia-a-dia quanto nas profissionais. Principalmente os homens mencionaram a frustração, a preocupação com o trabalho e a situação financeira, por compreenderem que a vida da família ficou sobrecarregada para os filhos e para a esposa depois que adoeceram. Expressaram que se sentiam ansiosos, frustrados e preocupados em "dar trabalho" para os filhos e para a esposa.

Apesar de a maioria dos participantes ser constituída por aposentados, eles exerciam um importante papel no núcleo familiar e contribuíam efetivamente com a renda mensal de sua família. Os participantes mencionaram que, após a cirurgia, a renda familiar ficou prejudicada em decorrência da incapacidade de desenvolver as atividades remuneradas que tinham antes da cirurgia. Mesmo os indivíduos aposentados necessitavam realizar outras atividades para complementar a renda; alguns, apesar de não desenvolverem nenhuma atividade remunerada que contribuísse para a renda familiar, ajudavam nos trabalhos domésticos, como capinar, limpar a casa, lavar roupas, dentre outros, assim o trabalho cotidiano também ficara prejudicado após a cirurgia.

De um modo geral, os participantes enfrentavam situações financeiras difíceis e os gastos familiares eram relacionados, principalmente, à manutenção da qualidade de vida familiar, à compra de medicamentos e à alimentação. Muitos afirmaram: “[...] se comprar comida, não compra o remédio. Se comprar o remédio, não come!"

Em um estudo sobre o cotidiano de indivíduos hipertensos, foi observado que as dificuldades mencionadas pelos pacientes no seguimento do tratamento da hipertensão arterial diziam respeito ao dinheiro para a compra de medicamentos, à necessidade de adequar-se à dieta sem sal, à distância percorrida até o serviço de saúde e ao dinheiro para o transporte ${ }^{(13)}$. Em outro estudo, as pesquisadoras apresentam o relato de uma paciente, que afirmou durante uma consulta médica, não estar usando o anti-hipertensivo em razão da falta da medicação no sistema de saúde e da dificuldade financeira para adquiri-la, o que a levou a ter que optar entre comprar a medicação ou alimentos ${ }^{(14)}$.

Em outro estudo, a enfermidade cardíaca, na perspectiva de indivíduos submetidos à revascularização miocárdica, foi interpretada como perda da saúde, sinalizada pela incapacidade de trabalhar e encontrar fontes de prazer. Os indivíduos relataram o aumento nos gastos financeiros familiares decorrentes da doença e da cirurgia (compra de medicamentos), que levara à piora das condições financeiras ${ }^{(15)}$.

Alguns relatos, em nosso estudo, ilustram essa percepção: “[...] a maior dificuldade depois da cirurgia é que tem que comprar o remédio direto e é caro! Não acha nos postinhos, o serviço que fazia não posso fazer mais, então fico me sentindo meio desprezado!" (S6, M, 47) ${ }^{2} ;$ “[...] depois que fiz a cirurgia consegui uma amostra grátis do remédio para colesterol, tomei um mais barato que me deram, depois parei, pois estava caro demais e não tinha como conseguir. Tentei no postinho, fiz tudo, mas por causa de um papel que o doutor esqueceu de assinar não consegui, aí deixei de mão." (S7, F, 46)

É necessário facilitar o acesso à informação e aos medicamentos no sistema de saúde, reduzindose os entraves burocráticos e o tempo gasto nesta tarefa. No entanto, a distribuição da medicação gratuita por si só não educa a população para a promoção da saúde. Neste sentido, torna-se fundamental que o sistema de saúde vigente adote estratégias efetivas para o cuidado com a saúde das pessoas, considerando seu contexto de vida socioeconômico e cultural como fatores importantes na individualização do acesso a bens e serviços de saúde, que, neste caso, envolvem desde a aquisição de medicamentos até o acesso à educação e à saúde ${ }^{(12)}$.

\section{O conhecimento de pacientes hipertensos revascularizados sobre a enfermidade cardíaca \\ Com base na análise dos relatos dos} participantes, foram descritos os conhecimentos dos indivíduos hipertensos revascularizados relacionados à descoberta da enfermidade cardíaca e às explicações para a coronariopatia e hipertensão arterial.

No núcleo temático a descoberta da enfermidade cardíaca, foram agrupadas as unidades de significado relacionadas à surpresa ao saber que o problema era no coração e a não-

2 Os participantes, cuja identidade é aqui devidamente preservada, são identificados pelos seguintes códigos: número do sujeito (por exemplo, $\mathrm{S1}$ ), letra correspondente ao sexo (M-masculino e Ffeminino) e idade. 
percepção do risco para a coronariopatia, relacionado, entre outros fatores, à hipertensão arterial.

Um dos aspectos referidos diz respeito ao fato de não terem, em momento algum, esperado passar por esta experiência. Mencionaram que não imaginavam que o mal-estar e a dor no peito, no queixo, nas costas e no pescoço pudessem ser um "possível" problema no coração. Percebiam que algo estava errado com o corpo, mas não associavam este fato ao problema cardíaco; na maioria das vezes, consideravam-se saudáveis e cheios de vida. Alguns disseram:

[...] antes meu problema era pressão alta, colesterol, mas pensava que meu coração era mil! Nunca pensava que tinha problema do coração. Nunca pensei que ia passar por uma cirurgia porque todas as vezes que eu fazia exame não dava nada. (S6, M, 47).

Eu sabia que tinha diabetes, pressão alta, mas não desconfiava que essa dor no peito era problema do coração. (S9, M, 56).

De modo semelhante ao que foi encontrado em outros estudos ${ }^{(12,15-16)}$, observou-se, nesta pesquisa, que a doença cardíaca surge em um momento inesperado, surpreendendo o indivíduo no apogeu de sua vida produtiva, o que o obriga a fazer mudanças drásticas no estilo de vida.

De modo geral, as pessoas não haviam percebido o risco de desenvolverem a doença cardíaca associado a outros fatores com os quais já conviviam. Alguns participantes descobriram o problema cardíaco por acaso, enquanto se preparavam para outra cirurgia; outros, ao procederem medição ocasional da pressão arterial e conseqüente investigação mais profunda. Os depoimentos revelam:

[...] a primeira vez que tive pressão alta comecei a sentir um aperto no pescoço, uma dor horrível! Corri para o Hospital do Coração. Aí que se determinou que eu tinha problema no coração. (S4, M, 73);

[...] estava me preparando para fazer a cirurgia do útero quando comecei a sentir dormência no braço, ficava com um pouco de palpitação, falta de ar, mas com o passar dos dias foi agravando mais, tanto que quando eu voltava da casa do meu filho à tarde, já sentia falta de ar e o braço esquerdo dormente. 0 ginecologista pediu o risco cirúrgico, fiz o exame de esteira, com isso procurei o cardiologista. (S2, F, 61);

[...] estava indo embora do serviço e senti uma pontadinha de nada, deu vontade de passar no postinho e medir a pressão, mas não estava sentindo nada, cheguei lá a pressão estava altíssima, ai já saí de lá direto para a UTI e me operaram. (S9, M, 56)

Dessa forma, a coronariopatia e os sintomas do problema cardíaco apareceram de modo silencioso e gradativo, sendo ignorados pelos participantes até o momento em que se tornaram intensos e geraram a necessidade de buscar atendimento especializado. A sintomatologia foi o principal fator para a descoberta do problema cardíaco. Um estudo aponta que metade da população que possui pressão alta ignora sua presença até que ela comece a se manifestar sob as formas de tonturas, dores de cabeça, alterações visuais, infartos e acidentes vasculares cerebrais ${ }^{(13)}$.

Neste estudo, todos relataram que, antes do problema cardíaco, mesmo sabendo que eram hipertensos, adotavam comportamentos de risco, como ingerir comida gordurosa, fazer uso do cigarro, não praticar exercícios físicos e não tomar regularmente a medicação para o controle da pressão arterial. Os participantes não identificavam a hipertensão como um fator de risco para a doença coronariana.

Em um estudo com onze sujeitos coronariopatas revascularizados foi verificado que, dos onze sujeitos coronariopatas revascularizados, dez eram hipertensos e, desses, apenas um fazia uso da medicação anti-hipertensiva regularmente antes de vivenciar o problema cardíaco. Os demais mencionaram que não tomavam a medicação, pois não sentiam nada, não achavam que a pressão estivesse alta ${ }^{(12)}$. Em nosso estudo, os participantes demonstraram ter essa mesma percepção:

[...] em 2001, fiz uma consulta, a doutora disse que eu tinha que tomar remédio para baixar a pressão, que minha pressão era muito alta e ao mesmo tempo o colesterol, achei que aquilo não era nada e não obedeci, me descuidei. (S5, M, 62);

[...] tinha colesterol alto, pressão alta e diabetes, mas nunca tomei remédio contínuo para pressão, nem nada, nem fazia regime, eu não continuava o tratamento, era só aquela receita que o médico passava e pronto. Eu nunca dei conta de fazer regime! (S6, $\mathrm{M}, 47)$;

[...] não sei por que internava direto, a única coisa que tinha certeza era da pressão, mas não tomava remédio, o doutor me passava um mundo de remédio para o coração, eu não precisava porque não sentia dor no peito! O único remédio que tomo toda a vida depois que tive o derrame foi o da pressão, para o coração não tomava, vim tomar agora depois da primeira cirurgia. (S11, F, 58).

Outro estudo, realizado com indivíduos que sofreram infarto, evidenciou que $16 \%$ dos participantes se reportaram ao infarto como uma doença repentina, caracterizando-a como acontecimento assustador e inesperado. Os indivíduos acreditavam que tal enfermidade nunca Ihes iria atingir, pois não sentiam nada no coração antes e, segundo relataram, se soubessem antecipadamente, teriam evitado sua ocorrência ${ }^{(16)}$. 
Em geral, o caráter silencioso e progressivo da doença cardiovascular faz com que os indivíduos tenham a falsa impressão de serem absolutamente saudáveis, em decorrência da ausência dos sintomas cardiovasculares. Desse modo, descuidam de sua saúde, deixando de tomar as medicações pelo fato de não sentirem nada. Os indivíduos associam a idéia de ir ao médico e fazer uso de medicamentos somente à presença de sintomas ${ }^{(17)}$.

A importância dada ao seguimento do tratamento da hipertensão arterial parece estar diretamente relacionada à compreensão que os indivíduos têm sobre a doença. Essa compreensão sofre influência da situação socioeconômica, do grau de instrução, dos sentimentos e conhecimento sobre a doença, do estilo de vida, da experiência anterior com a doença no meio em que vivem, da percepção da seriedade do problema e do relacionamento com a equipe de saúde. Geralmente, o seguimento do tratamento só é dado a partir do aparecimento de complicações $^{(13)}$, como afirma um dos sujeitos:

[...] teve um dia que fiz um teste, falei que ia ficar três dias sem tomar o remédio para vê se a pressão sobe, aí fiquei um dia sem tomar e sem comer nada salgado, mas quando chegou a noite já estava sentindo a cabeça doer, falei será que é pressão? Mas não tomei o remédio, não consegui dormi direito. No outro dia já estava melhor, mas quando foi à tarde estava sentindo pesado meus ombros, aí tomei o remédio, é tomar e melhorar, vi que não tem como ficar sem. (S7, F, 46).

A fala da participante demonstra que a adesão ao tratamento farmacológico só ocorreu mediante a experiência própria com os sintomas da hipertensão arterial, visto que se sentia vulnerável às conseqüências. Estudo realizado sobre a educação em saúde na atenção médica ao paciente com hipertensão arterial no programa de saúde da família demonstrou que $30 \%$ dos pacientes relataram a descontinuidade total ou parcial da medicação prescrita pelo médico, $18 \%$ afirmaram haver descontinuado o uso por conta própria e $12 \%$ referiram usar a medicação prescrita em desacordo com a orientação médica, freqüentemente reduzindo sua dosagem ${ }^{(14)}$.

Semelhantemente, em outra investigação sobre fatores de risco e dificuldades do hipertenso para o autocontrole, foi constatado que $37,17 \%$ dos participantes desconheciam o significado da hipertensão arterial e 35,40\% conheciam apenas parcialmente; dentre as complicações associadas à hipertensão arterial, a coronariopatia foi predominante, acometendo $52 \%$ dos participantes, seguida pela doença renal com 29,1\%. A conclusão foi que a falta de conhecimento e o cumprimento inadequado das orientações dos profissionais de saúde constituem fatores dificultadores da adesão ao tratamento, contribuindo para altas taxas de complicação, como a possível reincidência da coronariopatia ${ }^{(8)}$.

Os relatos nos permitem afirmar que, atualmente, o modelo de assistência à saúde predominante é o biomédico, curativista, centrado no ato médico e na queixa-conduta, por meio do pronto atendimento e da demanda espontânea, o que dificulta o controle das doenças crônicas. Torna-se necessário maior investimento em uma política voltada para a promoção da saúde e a prevenção das doenças, de forma que ocorra uma intervenção efetiva no atual panorama da saúde no país, com um enfoque que não seja somente a doença, mas tudo que a circunda ${ }^{(17)}$.

No núcleo temático as explicações para a doença cardíaca, foram agrupadas as unidades de significado em que, a partir da experiência e observações cotidianas, os sujeitos associaram a coronariopatia a outras condições crônicas de saúde, tais como diabetes, hipertensão arterial, acidente vascular encefálico e aspectos comportamentais associados ao estilo de vida.

É interessante destacar que, antes da cirurgia, os participantes não correlacionavam a hipertensão arterial ou outras condições crônicas de saúde ao problema cardíaco, apenas passaram a estabelecer essa relação ao receberem algumas informações dos profissionais da saúde ou a partir da experiência vivenciada.

Quando questionados se havia algum problema de saúde antes da descoberta do problema cardíaco, responderam negativamente, mesmo sabendo que tinham hipertensão arterial ou diabetes. Em geral, quando afirmavam que tinham algum problema de saúde, este era encarado como descuido. Alguns relatos ilustram essa percepção:

[...] tinha colesterol alto, pressão alta e diabetes, mas nunca tomei remédio contínuo para pressão, nem nada, não continuava o tratamento, era só aquela receita que o médico passava e pronto. [...] o médico disse que o causador do infarto foram essas três coisas, pressão alta, diabetes e colesterol. Então acho que a pressão alta é um risco para quem tem problema, junto com o colesterol alto e a diabetes pode levar a gente até a morte, são bem perigosas. (S6, M, 47)

Ao investigarem os conhecimentos, as atitudes e os comportamentos relacionados à hipertensão arterial, pesquisadores observaram que os sujeitos da pesquisa conheciam a hipertensão arterial assim como os fatores comportamentais de risco relacionados à sua ocorrência, porém esse conhecimento advinha das vivências no próprio corpo, entre os membros da família ou no ambiente em que vivem e difere, em alguns pontos, do conhecimento elaborado pela ciência. Os autores 
discutiram que, apesar de as pessoas terem conhecimento sobre a doença, poucos mostravam motivação real para a adesão ao tratamento. Explicações para esse fato podem ser a evolução silenciosa e a cronicidade da doença retratando que, mesmo após o diagnóstico e a existência de uma grande diversidade terapêutica eficaz para o controle das doenças crônicas, grande parte dos milhões de brasileiros, que se estima possuir a doença, continua ignorando- $\mathrm{a}^{(18)}$.

Os sujeitos da presente pesquisa também correlacionaram aspectos comportamentais associados ao estilo de vida com fatores que causaram diretamente a coronariopatia e a hipertensão arterial. Os fatores destacados foram: hábitos alimentares inadequados, consumo de bebida alcoólica, fumo e até mesmo o descuido com a saúde, referidos como fatores cruciais para a causa da coronariopatia. Em geral, eles relataram que vivenciavam situações de estresse no cotidiano, ingeriam comida gordurosa, fumavam, bebiam, não praticavam exercícios físicos, não iam ao médico e se preocupavam apenas com o trabalho e a provisão financeira da família. Os participantes reconheceram o estilo de vida como fator de risco e como causa da doença cardíaca, mas isso só ocorreu após a experiência da enfermidade.

Um aspecto peculiar desse grupo social é que, embora hipertensos, a maioria não via a saúde como prioridade e, sim, o trabalho e o cuidado com a família. Alguns disseram:

[...] a gente que é da roça não preocupa (com a saúde), preocupa mais é com trabalho, não preocupa em fazer exame, em ir ao médico, ver o corpo da gente para ver como que você está, preocupa mais é só com o serviço, é trabalha, é trabalha, é trabalha, quando você adoece é hora. (S3, M, 74);

[...] sempre ia no clínico geral por causa da pressão alta, tomava vários remédios e eles falavam para procura um cardiologista, mas nunca procurei o cardiologista, devido ao tempo, ao trabalho, aos atropelos da vida deixava para amanhã. [...] o meu maior erro foi não ter procurado o médico antes, mas não procurei pela parte financeira, tinha família para cuidar, você ir nesse SUS tudo tem que ser através de encaminhamento e é muito demorado. Então não podia matar serviço para correr atrás disso, quer dizer quase perdi minha vida porque não corri atrás. (S12, F, 51).

A bebida alcoólica, os hábitos alimentares inadequados, o fumo, o sedentarismo e o estresse também foram fatores apontados pelos participantes como causa da doença cardíaca:

[...] fumei desde os 18 anos, todos os dias, era uma carteira e meia por dia praticamente, essa doença eu que provoquei, fumando, bebendo, eu trouxe isso para mim, o que plantei, hoje estou colhendo, mas acho que estou colhendo mais do que plantei. (S9, M, 56);

[...] acho que o cigarro pode ter dado uma contribuição grande, pois fumava umas 3 carteiras de cigarro por dia, mas tinha parado há 6 anos e engordei, não fazia exercício, acho que isso também influenciou, vem de família também. (S10, M, 67)

Indivíduos coronariopatas revascularizados relacionaram a coronariopatia aos hábitos alimentares anteriores, mencionando terem feito uso de alimentos gordurosos, que, na sua perspectiva, simbolizava uma comida gorda, gostosa e com "sustância"(12). Dados semelhantes foram encontrados nesse estudo, visto que os participantes relataram se alimentar basicamente de arroz, feijão e carnes, preparados com gordura animal (banha de porco). Os sujeitos mencionaram o uso de alimentação gordurosa, justificando que não sentiam nada:

[...] eu comia muita carne gorda, torresmo, leite, tomava dois a três litros de leite por dia, fui criado com leite gordo da fazenda, então como eu não sentia nada [...]. (S5, M, 62);

[...] o maior fator (para doença cardíaca) é comida gorda! Nossa comida era gorda e mais carne de gado, aquela manteiga entope, ela coalha, é comida que entope as veias. (S3, M, 74);

[...] o problema do coração é um saco de pancadas onde tudo que você faz, fez na sua cabeça vai direto para lá, ele que agüenta tudo isso. [...] eu era uma pessoa sadia, não sei se as frituras, churrasquinhos, cervejinha me levaram a fazer a cirurgia, pois para dizer a verdade gostava de carne mais gordurosa. [...] acho que foi mesmo o estresse, somado com os outros fatores, alimentação. (S4, M, 73);

[...] creio que foi alimentação errada, acho que a gordura da manteiga de leite entupiu minhas veias, principalmente essa manteiga de leite além de outras coisas que a gente come, pois sempre fui chegado a comer comida gordurosa, sempre escolhia a carne mais gorda. (S8, M, 59).

O cigarro, o sedentarismo e o estresse também foram citados pelos participantes como causas da doença cardíaca. Alguns mencionaram que não sabiam que o cigarro representava possível risco para a saúde:

[...] naquela época eu passava mal, mas não sabia ainda, não tinha consciência que o cigarro fazia tão mal e continuava fumando e passando mal, até quando fiquei internada na UTI. (S7, F, 46); [...] eu que provoquei essa doença, fumando, bebendo. (S9, $\mathrm{M}, 56)$;

[...] acho que foi sedentarismo, medo, agitação, estresse devido a vida difícil que levei, trabalhei muito, passei sérias dificuldades com meu esposo, agüentava muitas coisas caladas, pois ele bebia, eu ficava com medo, agitada, o meu coração só faltava 
saltar, tudo isso foi entupindo as veias, porque eu creio que comida não foi, eu não comia gordura!. (S2, F, 61);

[...] acho o que levou a esse problema foi mais o estado emocional, mesmo porque tive muitas perdas uma atrás da outra, perdi meu pai, minha mãe e meu filho, que foi a que mais me arrasou porque foi através de um suicídio, então é uma coisa que a gente não espera, meu estado emocional nunca mais chegou ao normal. (S12, F, 51).

Com base na interpretação dos relatos acerca das explicações para o problema cardíaco, percebemos a complexidade da realidade social analisada, uma vez que são as experiências vivenciadas por esses indivíduos que fundamentam seus conhecimentos. Observou-se também que, diante de tantos aspectos etiológicos do problema cardíaco vivenciado, eles faziam uma inter-relação entre os vários fatores de risco. Algumas falas explicitam isso:

[...] uma coisa ataca a outra, pressão alta, colesterol alto, veia entupida, está tudo ruim em mim! Não tem nada bom?! (S3, M, 74);

Eu não acreditava em estresse, para mim isso era só de dondoquinha, essas coisas, mas existe mesmo e para mim foi isso junto com minha alimentação. Beber, fumar, fazer essas coisas sem limite acho que também me prejudicou muito. (S7, F, 46).

Podemos observar que os fatores de risco para as doenças cardiovasculares estão intimamente interligados e que os indivíduos possuem conhecimento de tais fatores, mesmo que de modo pouco elaborado. O estilo de vida parece estar relacionado ao prazer que estes sentem ao praticar determinados comportamentos como fumar, ingerir bebidas alcoólicas e comer. Assim, o abandono desses hábitos pode significar perda de prazer em um contexto de vida no qual as oportunidades de satisfação pessoal são muito poucas. É necessário que os profissionais de saúde levem em consideração os hábitos e os valores atribuídos pelo indivíduo à alimentação para que consigam fazer uma dieta balanceada, porém sem restringir muito sua liberdade de escolha(18).

A partir da descrição da experiência da enfermidade e dos problemas socioeconômicos vivenciados pelos participantes do estudo, ficou evidenciado que a cirurgia cardíaca marca uma ruptura no modo de viver, de trabalhar, de compreender o processo saúde-doença e na posição social no núcleo familiar ${ }^{(12)}$. Embora os participantes tenham mencionado que a vida melhorou após a cirurgia e que agora cuidavam de sua saúde, em algumas declarações, tanto os comportamentos expressos como aqueles observados retratavam a dificuldade da mudança de estilo de vida, principalmente relacionada ao uso das medicações.
Nesse aspecto, encontramos duas situações distintas: alguns sujeitos mantinham hábitos anteriores e não faziam uso das medicações prescritas pelo médico em razão da ausência de sintomas; outros afirmaram não ter condições financeiras para comprar medicações de alto custo como a medicação antilipêmica.

Considera-se fundamental, no período de reabilitação, um programa de educação em saúde que inclua o acompanhamento periódico para esclarecer estes pacientes sobre suas responsabilidades, possíveis perdas e ameaças a que estão expostos, de modo que eles tenham condições de se autocuidar e de compreender as limitações impostas pela coronariopatia e a hipertensão arterial $^{(7)}$.

\section{As necessidades de aprendizagem relacionadas à enfermidade cardíaca}

As necessidades de aprendizagem relacionadas à enfermidade cardíaca foram identificadas por meio da interpretação dos relatos. Neste processo, ficou evidenciada a deficiência do conhecimento que tinham os sujeitos acerca do processo de adoecimento que envolveu a coronariopatia, a hipertensão arterial e sua conseqüente dificuldade em adequar-se aos novos hábitos de vida. Os núcleos temáticos identificados expressam a necessidade que tinham os participantes do estudo de aprender sobre as causas da enfermidade cardíaca e os cuidados preventivos para cuidar bem do coração.

No núcleo temático as causas da enfermidade cardíaca foram agrupadas as unidades de significado relacionadas às dúvidas expressas pelos sujeitos referentes ao que causou a coronariopatia e a hipertensão arterial. Apesar de terem explicado o problema cardíaco, como descrito anteriormente, os sujeitos mencionaram que, antes da realização da cirurgia, não correlacionavam outras condições crônicas de saúde, como a hipertensão arterial, com o risco para a coronariopatia.

Ao longo das entrevistas, pôde-se observar que, em busca de explicações para a enfermidade cardíaca, os indivíduos apresentaram relatos cheios de dúvidas, controvérsias e dificuldades para expressar seus próprios conhecimentos, apresentando conceitos vagos e até mesmo confusos. $\mathrm{O}$ interesse em conhecer mais sobre o processo de adoecimento tornou-se mais aguçado a partir do momento em que sentiram a necessidade de compreender o que os levou ao processo de adoecimento e, assim, "evitar um mal maior no futuro".

Entre as necessidades de aprendizagem, referentes à causa da enfermidade cardíaca, os sujeitos destacaram: 
[...] gostaria de saber o porquê, qual o problema que provocou essa doença (doença cardíaca) em mim, se foi através de comida, bebida, esforço físico, falta de paciência (S6, M, 47);

[...] gostaria de saber como que começa a entupir as veias, se é o sal, gordura ou se é a comida (S3, M, 74);

Não entendo porque minha pressão está alta agora, após a cirurgia, pois a veia não está entupida, não devia estar alta. Antes a pressão subia devido as veias entupidas, tinha uma restrição para passar, então aumentava a pressão, entendo assim, se não houver restrição ele vai passar naturalmente sem excesso de pressão (S8, M, 59);

[...] gostaria de saber como que essa danada (pressão arterial) começa e te acaba, como que faz para ficar livre dela, sem ela aumentar, não tomar mais remédio ( $S 7, \mathrm{~F}, 46)$;

[...] gostaria de saber o básico mesmo, saber quais as conseqüências da pressão alta no organismo, qual é alimentação, saber educar o estômago para comer aquilo que não faz mal para ele (S9, M, 56);

[...] gostaria de saber o porquê, que mesmo tomando remédio para a pressão ela não normaliza. Tomei remédio há 32 anos, larguei de fumar, de beber, de comer gorduras para ver se a minha pressão normalizava e não fosse necessário fazer essa cirurgia, no entanto não resolveu não sei o porquê. (S12, F, 51).

As declarações demonstram que os indivíduos gostariam de conhecer os fatores associados à coronariopatia, principalmente após a cirurgia, pelos quais a pressão arterial não retornara a seu valor normal sem que houvesse a necessidade de tomar medicamentos. Em pesquisa realizada com objetivo de identificar o que os indivíduos portadores de hipertensão arterial pensam sobre a doença, percebeu-se a dificuldade que essas pessoas têm em conceituar a doença; ficou claro, porém, que a grande maioria procura associá-la a algo: 50\% associaram aos fatores de risco; 24\%, às complicações; $8 \%$, aos sintomas; $5 \%$ não fizeram qualquer associação e $1 \%$ associou a medidas terapêuticas ${ }^{(19)}$

O conhecimento da doença e do regime de tratamento é fundamental para o indivíduo se autocuidar, o que aumenta a habilidade de controle. Assim, o indivíduo que não conhece seu estado de saúde e tampouco os comportamentos e práticas saudáveis manifesta resistência em aderir ao tratamento, ao autocuidado e até mesmo a desenvolver práticas preventivas, o que, às vezes, ocasiona reinternações ${ }^{(20)}$.

Em estudo realizado para avaliar como acontece a educação de pacientes internados nas clínicas médica, cirúrgica e neurológica em um hospital geral, $50 \%$ dos pacientes entrevistados disseram possuir dúvidas sobre o diagnóstico e sobre cuidados que deveriam tomar para conviver melhor com a doença a fim de evitar a sua reincidência. O estudo demonstrou que, independentemente do diagnóstico, esses indivíduos iam para casa sem nenhuma instrução e que, somente após a demonstração de interesse e capacidade de aprender, as informações eram fornecidas pelos profissionais ${ }^{(20)}$.

Pesquisadores observaram, em um estudo sobre a educação em saúde na atenção médica ao paciente com hipertensão arterial, que os médicos são levados a compartilhar mais informações com os pacientes mais questionadores, o que não ocorre espontaneamente em consultas nas quais o paciente assume uma postura mais passiva. No mesmo estudo, a análise de 50 consultas médicas com pacientes hipertensos conduzidas por dez médicos atuantes revelou que apenas um assumiu uma abordagem que favorecia a visualização do indivíduo e não de sua doença. Somente esse profissional estabeleceu uma relação dialógica com o paciente, levando em consideração seu contexto socioeconômico, respondendo seus questionamentos e verificando a compreensão do paciente acerca das informações passadas ${ }^{(14)}$.

No núcleo temático os cuidados preventivos necessários para a coronariopatia e hipertensão arterial, foram agrupadas as unidades de significado relacionadas à aprendizagem necessária para a adoção de um novo estilo de vida saudável.

Os participantes relataram que dúvidas e dificuldades referentes à adoção dos novos hábitos de vida estavam relacionadas à adequação da dieta, ao uso regular da medicação e à prática de exercícios físicos. Informações sobre esses temas Ihes possibilitariam saber se o que estavam fazendo era realmente o ideal para uma melhoria na qualidade de vida:

[...] acho o que evita a pressão alta deve ser as comidas, comida mais light, mais fraca, mas comendo comida fraca depois a anemia te pega, como é que faz? (S6, M, 47);

[...] gostaria de saber se a gente fazer muito exercício se prejudica ou se ficar parado é melhor, se é pior, quais são os cuidados que a gente tem que tomar. (S6, M, 47);

[...] gostaria de saber sobre os cuidados que tem que ter com o coração porque ele é a máquina da gente. (S12, F, 51);

[...] gostaria de saber como evitar a doença do coração porque creio que tem jeito de evitar, então queria que dessem uma explicação. (S10, M, 67).

Pesquisadores relatam que existe uma lacuna entre o que pacientes hipertensos acreditam que podem fazer e o que realmente fazem em relação ao autocuidado $^{(5)}$. Em um levantamento dos hábitos de saúde relacionados aos fatores de risco em indivíduos 
hipertensos hospitalizados, a maioria dos participantes demonstrou saber a importância do controle dos fatores de risco para a hipertensão arterial, sendo os fatores mais apontados o controle do sal $(96,9 \%)$ e a restrição de gorduras $(93,7 \%)^{(6)}$.

O processo de adaptação às modificações no estilo de vida dos hipertensos é bastante complexo e está diretamente relacionado ao seguimento do tratamento para o controle da hipertensão arterial. A adesão ao tratamento implica dificuldades, como a ingestão de dieta hipossódica e o estabelecimento de uma rotina de tomada das medicações ${ }^{(13)}$.

Nas falas seguintes, percebemos o reconhecimento da necessidade de aprendizagem:

[...] eu tenho arrependimento de eu mesmo não ter tomado providência, porque isso ninguém podia fazer nada a não ser eu mesmo porque fui avisado, estava consciente que tinha pressão alta e colesterol, mas não tomei providência! (S5, $M, 62)$;

[...] deveria ter um esclarecimento, não da cirurgia, mas do diabetes e de outras doenças, quer dizer a televisão falava, estava na parte escrita do jornal, mas a pessoa não leva muito a sério, faltou que meu pai me pegasse e falasse olha eu tenho diabetes isso é hereditário você se cuida por isso e por isso! Então o que falta é a pessoa se conscientizar dizer estou com diabetes então vou me cuidar, mas esse ponto está bem ligado a própria pessoa porque ninguém vai pegar uma idéia de diabetes e enfiar na cabeça do outro se ele não quer aprender não adianta ele vai continuar até sentir em carne própria o que o diabetes. Acho que não é problema dos órgãos públicos, nem das fábricas de produtos, eles já estão fazendo o que tinham que fazer. O estado e demais, universidades já fizeram seu papel agora o papel é da própria pessoa se conscientizar. (S4, M, 73);

[...] atendimento mais para prevenir as coisas, sobre comida, prevenir para vê se não entupia as veias porque se a gente soubesse como que era, como agir a gente tinha que prevenir mais. Ter uma pessoa para explicar para a gente que se você comer, beber isso faz mal, entope as veias, dá cirrose, você vai morrer porque ataca as veias, o coração, e fosse explicando para a gente tudo o que fosse fazer... mas você vive neutro, ninguém explica, só explica para a gente só depois que você está lá. (S3, M, 74).

As declarações acima reafirmam a necessidade de um programa de educação em saúde conscientizador e participativo, que possibilite a troca de vivências. É necessário identificar o que as pessoas pensam e sabem sobre o processo saúdedoença vivenciado para que seja criado um vínculo de confiança entre profissional e paciente com o objetivo de desenvolver no sujeito a coresponsabilidade por sua saúde ${ }^{(12)}$.

\section{CONSI DERAÇÕES FI NAIS}

Com a realização deste estudo, compreendemos que cuidar da saúde de indivíduos hipertensos revascularizados deve ser uma prioridade para prevenir e modificar o atual panorama insatisfatório de controle da pressão arterial. É necessário que os profissionais de saúde utilizem métodos de educação em saúde que atendam às necessidades de conhecimento dos indivíduos acerca do processo saúde-doença e que contribuam para que eles, efetivamente, incorporem às suas vidas atitudes que promovam sua saúde.

O processo educativo justifica-se pela necessidade tanto de promover, por meio da reflexão-ação, a tomada de consciência dos potenciais riscos relacionados à saúde quanto de estimular o indivíduo a assumir o autocuidado e a responsabilidade compartilhada no que se refere às mudanças em seus hábitos de vida.

É preciso considerar que a modificação de comportamento é um processo difícil, que não envolve somente a aquisição de informações, mas também o desenvolvimento de um trabalho de suporte realizado ao longo do tempo para que o indivíduo desenvolva a intenção de mudança de comportamento e, posteriormente, a concretize. A educação deve ser voltada para "o que o paciente precisa fazer para ter saúde" e não apenas para o que ele deve saber. Observou-se a necessidade de maiores esclarecimentos sobre a patologia; portanto, devem ser usadas estratégias eficazes para que as orientações necessárias sejam transmitidas de acordo com o contexto sociocultural dos indivíduos e, conseqüentemente, assimiladas.

Compreender os pensamentos e o déficit de conhecimentos dos hipertensos revascularizados é importante para a construção de modelos de atenção que considerem o sujeito como participante ativo, com autonomia para fazer escolhas e definir prioridades em sua vida. Assim, torna-se necessário proporcionar a esses indivíduos educação e saúde após a cirurgia e durante a reabilitação cardíaca, de modo que tenham a oportunidade de conviver harmonicamente com sua condição crônica de saúde, tendo uma melhor qualidade de vida.

\section{REFERÊNCI AS}

1. Sociedade Brasileira de Cardiologia. III Diretrizes brasileiras sobre dislipidemias e diretriz de prevenção da aterosclerose do departamento de aterosclerose da Sociedade Brasileira de Cardiologia. Arq. Bras. Cardiol. 2001; 77(suppl.3):1-48.

2. Gomes MAM, Nobre F, Amodeo C, Mion Jr D, Kohlmann Jr O, Praxedes JN, Machado CA. IV Diretrizes brasileiras de hipertensão arterial. Arq. Bras. Cardiol. 2004; 82(suppl.IV): 7-14. 
3. Pessuto J, Carvalho EC. Fatores de risco em indivíduos com hipertensão arterial. Rev Latino-am Enfermagem. 1998;6(1):33-9.

4. Jardim AR, Moura LF, Silqueira SMF. A importância de uma assistência diferenciada ao cliente hipertenso visando à adesão ao tratamento proposto. In: Anais do 8o Encontro de Extensão da UFMG; 2005 Oct 0308; Belo Horizonte, Brasil. 2005.

5. Peres DS, Magna JM, Viana LA. Portador de hipertensão arterial: atitudes, crenças, percepções, pensamentos e práticas. Rev. Saúde Públ. 2003; 37(5): 635-42.

6. Simonetti JP, Batista L, Carvalho LR. Hábitos de saúde e fatores de risco em pacientes hipertensos. Rev Latino-am Enfermagem. 2002; 10(3): 415- 22.

7. Dantas RA, Aguillar OM. Problemas na recuperação de pacientes submetidos à cirurgia de revascularização do miocárdio: o acompanhamento pelo enfermeiro durante o primeiro mês após a alta hospitalar. Rev Latino-am Enfermagem. 2001;9(6): 26-31.

8. Fava SMCL, Botelho FF, Seabra ER, Rodrigues LBB, Nagaoka AP. Educação e Controle da Hipertensão. In: Anais do 2o Encontro de Extensão da UFMG; 2004 Oct 12-15; Belo Horizonte, Brasil. 2004.

9. Yin RK. Case study research, design and methods. 3rd. ed. Newbury Park: Sage Publications; 2002.

10. Strauss A, Corbin J. Pesquisa qualitativa: técnicas e procedimentos para o desenvolvimento de teoria fundamentada. 2nd ed. Porto Alegre: Artmed; 2008.

11. Miles MB, Huberman AM. Qualitative data analysis: an expanded sourcebook. 2nd ed. London: Sage Publications; 1994.

12. Vila VSC. O significado de qualidade de vida: perspectivas de indivíduos revascularizados e de seus familiares [thesis]. Ribeirão Preto: Escola de Enfermagem/USP; 2006.

13. Castro VD, Car MR. O cotidiano da vida de hipertensos: mudanças, restrições e reações. Rev. esc. enferm. USP. 2000; 34(2): 145-53.

14. Alves VS, Nunes MO. Educação em saúde na atenção médica ao paciente com hipertensão arterial no Programa Saúde da Família. Interface. 2006; 10(19): 131-47.

15. Vila VSC, Rossi, LA, Costa MCS. Experiência da doença cardíaca entre adultos submetidos à revascularização do miocárdio. Rev. Saúde Públ. 2008; 42(4): 750-6.

16. Santos FLM, Araújo TL. Vivendo infarto: os significados da doença segundo a perspectiva do paciente. Rev Latino-am Enfermagem. 2003; 11(6): 742-8.

17. Maciel EAB. Estudo da adesão ao tratamento da hipertensão arterial [dissertation]. Ribeirão Preto: Escola de Enfermagem/USP; 1997.

18. Lima MT, Bucher JSNF, Lima JWO. A hipertensão arterial sob o olhar de uma população carente: estudo exploratório a partir dos conhecimentos, atitudes e práticas. Cad. Saúde Pública. 2004;20(4): 1079-87.

19. Dell'acqua MCQ, Pessuto J, Bocchi SCM, Anjos RCPM. Comunicação da equipe multiprofissional e indivíduos portadores de hipertensão arterial. Rev Latino-am Enfermagem. 1997;5(3): 43-8.

20. Rocha KPWF. Educação em saúde no ambiente hospitalar. Revista Nursing. 2007; 108(9):216-21.

Artigo recebido em 19.02.08.

Aprovado para publicação em 25.05.09. 